\title{
Novel docetaxel-loaded nanoparticles based on PCL-Tween 80 copolymer for cancer treatment
}

This article was published in the following Dove Press journal:

International Journal of Nanomedicine

31 October 20 I I

Number of times this article has been viewed

\section{Yuandong $\mathrm{Ma}^{1,2^{*}}$ \\ Yi Zheng ${ }^{1,2^{*}}$ \\ Xiaowei Zeng ${ }^{1-3^{*}}$ \\ Liqin Jiang ${ }^{4}$ \\ Hongbo Chen ${ }^{1,2}$ \\ Ranyi Liu ${ }^{5}$ \\ Laiqiang Huang ${ }^{1,2}$ \\ Lin $\mathrm{Mei}^{1,2}$}

'School of Life Sciences, Tsinghua University, Beijing, ${ }^{2}$ Division of Life and Health Sciences, Graduate School at Shenzhen, Tsinghua University, Shenzhen, Guangdong, ${ }^{3}$ Materials and Environment Experimental Center. Department of Materials Science and Engineering, Qinhuangdao Branch, Northeastern University, Qinhuangdao, ${ }^{4}$ Insitute of Biomedical Engineering, Peking Union Medical College, Chinese Academy of Medical Sciences, Tianjin, ${ }^{5}$ State Key Laboratory of Oncology in South China, Sun Yat-sen University Cancer Center, Guangzhou, People's Republic of China

*These authors contributed equally to this work
Correspondence: Lin Mei L40I, Tsinghua Campus, Xili University Town, Shenzhen, Guangdong Province 5I8055, People's Republic of China Tel +86755 26036736 Fax +8675526036736 Email mei.lin@sz.tsinghua.edu.cn
Background: The formulation of docetaxel available for clinical use (Taxotere ${ }^{\circledR}$ ) contains a high concentration of polysorbate 80 (Tween 80). After incorporation of Tween 80 into poly- $\varepsilon$-caprolactone (PCL)-Tween 80 copolymer, the relative amount of Tween 80 should be decreased and the advantages of PCL and Tween 80 should be combined.

Methods: A novel PCL-Tween 80 copolymer was synthesized from $\varepsilon$-caprolactone and Tween 80 in the presence of stannous octoate as a catalyst via ring opening polymerization. Two types of nanoparticle formulation were made from commercial PCL and a self-synthesized PCL-Tween 80 copolymer using a modified solvent extraction/evaporation method.

Results: The nanoparticles were found by field emission scanning electron microscopy to have a spherical shape and be $200 \mathrm{~nm}$ in diameter. The copolymers could encapsulate $10 \%$ of the drug in the nanoparticles and release $34.9 \%$ of the encapsulated drug over 28 days. PCL-Tween 80 nanoparticles could be internalized into the cells and had higher cellular uptake than the PCL nanoparticles. The drug-loaded PCL-Tween 80 nanoparticles showed better in vitro cytotoxicity towards C6 cancer cells than commercial Taxotere at the same drug concentration.

Conclusion: Nanoparticles using PCL-Tween 80 copolymer as drug delivery vehicles may have a promising outcome for cancer patients.

Keywords: cancer chemotherapy, docetaxel, nanoparticles, PCL-Tween 80

\section{Introduction}

Cancer remains a major health problem worldwide. The use of polymeric nanoparticles as drug delivery vehicles for anticancer therapeutics has great potential to revolutionize the future of cancer therapy. However, nanoparticles can be rapidly eliminated/excreted by macrophages in the reticuloendothelial system located primarily in the liver and spleen, resulting in a short half-life in the circulation after intravenous administration. ${ }^{1}$ Various attempts have been made to achieve a longer circulation time to avoid or reduce the absorption of nanoparticles onto phagocytes. ${ }^{2}$ Previous studies have shown that nanoparticles coated with a neutral hydrophilic outer layer can generate stealth particles and decrease phagocytic uptake, and thus significantly increase the blood circulation time with a high level of drug concentration in nonreticuloendothelial organs, such as the intestines and kidney. ${ }^{3,4}$ A number of surfactants, such as poloxamines, ${ }^{4}$ poloxamers, D- $\alpha$-tocopheryl polyethylene glycol 1000 succinate (TPGS), ${ }^{5}$ polyethylene glycol, ${ }^{6}$ and Tween $80^{4,7}$ have been used as coating materials. Importantly, some coating surfactants may help nanoparticles cross the gastrointestinal and blood-brain barriers. ${ }^{8,9}$ Systemically administered chemotherapy is often ineffective in the treatment of central nervous system diseases. One reason 
for this low efficacy is insufficient drug delivery to the brain due to the presence of the blood-brain barrier, which restricts exchange of solutes between the blood and extracellular brain fluid. Tween 80-coated nanoparticles have been reported to have the ability to transport loaded drugs across the blood-brain barrier after intravenous injection. ${ }^{8-10}$ It has been reported that polybutylcyanoacrylate nanoparticles are able to deliver hexapeptide dalargin, doxorubicin, and other agents which are significantly obstructed by the blood-brain barrier. ${ }^{11}$ This may be because the nanoparticles can adsorb apoliproprotein E, which mimics low-density lipoprotein, onto the nanoparticle surface and thus be uptaken via receptor-mediated endocytosis by endothelial cells in the brain capillaries. ${ }^{12-15}$ It was reported that Tween 80 -coated polybutylcyanoacrylate nanoparticles could enhance brain concentrations of administered doxorubicin by about 60 -fold in mice. ${ }^{16}$ Tween 80 is a polyethylene sorbitol ester, with a calculated molecular weight of $1310 \mathrm{Da}$, assuming 20 ethylene oxide units, one sorbitol, and one oleic acid as the primary fatty acid. Tween 80 is widely used in biochemical applications, including for solubilizing proteins, isolating nuclei from cells in cell culture, growing tubercle bacilli, and emulsifying and dispersing substances in medicinal and food products. ${ }^{17}$

Docetaxel is one of the most potent anticancer agents, and has activity against a wide range of tumors. Its commercial formulation, Taxotere ${ }^{\circledR}$, is formulated with a high concentration of Tween $80(40 \mathrm{~g} / \mathrm{L})$, which has been found to have severe side effects, including hypersensitivity reactions, cumulative fluid retention, nausea, mouth sores, fatigue, hair loss, peripheral neuropathy, and anemia, and has shown incompatibility with commonly used polyvinyl chloride intravenous administration sets. ${ }^{18}$ Therefore, investigation of alternative formulations of docetaxel without Tween 80 or with addition of a low concentration of Tween 80 is under way, and several approaches based on docetaxel conjugation, ${ }^{19}$ nanoparticles, ${ }^{20}$ liposomes, ${ }^{21}$ polymeric nanoparticles, ${ }^{22}$ micelles, ${ }^{23}$ and prodrugs ${ }^{24}$ have been proposed. In addition, poly- $\varepsilon$-caprolactone (PCL) is a very attractive synthetic polymer due to its properties of high permeability, lack of toxicity, and biodegradability. ${ }^{25}$ In this research, we developed PCL-Tween 80 as a novel copolymer and a novel PCL-Tween 80 nanoparticle as a potential drug carrier for cancer chemotherapy. Using this design, the relative amount of Tween 80 would be decreased and the advantages of PCL and Tween 80 would be combined after the incorporation of Tween 80 into a PCL-Tween 80 copolymer.

\section{Materials and methods \\ Materials}

PCL (molecular weight 42,000 Da), stannous octoate $\left[\mathrm{Sn}\left(\mathrm{OOCC}_{7} \mathrm{H}_{15}\right)_{2}\right]$, and Tween 80 were supplied by Sigma-Aldrich (St Louis, MO). The monomer, $\varepsilon$-caprolactone, was purchased from Acros Organics (Geel, Belgium). TPGS $\left[\mathrm{C}_{33} \mathrm{O}_{5} \mathrm{H}_{54}\left(\mathrm{CH}_{2} \mathrm{CH}_{2} \mathrm{O}\right)_{23}\right]$ was from Pubmed Co, Ltd, (Shenzhen, China). Docetaxel of purity 99.8\% was purchased from Pubmed. Fetal bovine serum was obtained from Gibco (Life Technologies, AG, Switzerland). Acetonitrile and methanol were purchased from EM Science (ChromAR, high-pressure liquid chromatography grade, Mallinckrodt Baker, Phillipsburg, NJ). All other chemicals used were of the highest quality commercially available. Ultrapure water produced by Boon Environmental Industry Co, Ltd, (Tianjin, China) was used throughout all the experiments.

\section{Synthesis of PCL-Tween 80 copolymer}

As shown in Figure 1, PCL-Tween 80 copolymer was synthesized from $\varepsilon$-caprolactone and Tween 80 in the presence of stannous octoate as a catalyst via ring opening polymerization. Briefly, $9 \mathrm{~g}$ of $\varepsilon$-caprolactone, $1 \mathrm{~g}$ of Tween 80 , and $0.02 \mathrm{~mL}$ of stannous octoate were added to a flask. The mixture was heated to $160^{\circ} \mathrm{C}$ and allowed to react for 12 hours. Synthesis was carried out in an oxygen-free and moisture-free environment. The product was dissolved in dichloromethane and then precipitated in excess cold methanol to remove unreacted $\varepsilon$-caprolactone monomers and Tween 80 . The final product was collected by filtration and vacuum-dried at $45^{\circ} \mathrm{C}$ for two days.

\section{Characterization of PCL-Tween 80 copolymer}

A Fourier transform infrared spectrophotometer (Thermo Nicolet, Madison, WI) was used to investigate the molecular structure of the PCL-Tween 80 copolymer. Briefly, samples for Fourier transform infrared analysis were prepared by grinding $99 \% \mathrm{KBr}$ with $1 \%$ copolymer and then pressing the mixture into a transparent tablet. The Tween 80 content and numberaveraged molecular weight of the copolymer were determined by ${ }^{1} \mathrm{H}$ nuclear magnetic resonance (NMR) in $\mathrm{CDCl}_{3}$ at $300 \mathrm{~Hz}$ (Bruker ACF300). The weight-averaged molecular weight and molecular weight distribution were determined by gel permeation chromatography. Thermogravimetric analysis (TGA 2050 thermogravimetric analyzer, Perkin Elmer, Waltham, MA) was carried out to investigate the thermal properties of the copolymer. During thermogravimetric 
analysis, about 5-15 mg of the copolymer sample was heated from $0^{\circ} \mathrm{C}$ to $600^{\circ} \mathrm{C}$ at a rate of $10^{\circ} \mathrm{C} /$ minute. The weight loss pattern in the copolymer thermogram could be related to the composition of the copolymer.

\section{Preparation of docetaxel-loaded nanoparticles}

The nanoparticles were prepared by a solvent extraction/ evaporation method with slight modification. ${ }^{18}$ Briefly, with a theoretical loading of $10 \%, 11.1 \mathrm{mg}$ of docetaxel and $100 \mathrm{mg}$ PCL-Tween 80 copolymer were dissolved in $8 \mathrm{~mL}$ dichloromethane to prepare the nanoparticles. The solution formed was poured into $120 \mathrm{~mL}$ of $0.03 \%$ (w/v) TPGS solution under gentle stirring. The mixture was sonicated for 120 seconds at $25 \mathrm{~W}$ output to form an oil/water emulsion. The emulsion was then evaporated overnight under reduced pressure to remove the dichloromethane. The particle suspension was centrifuged at 23,000 rpm for 15 minutes and then washed three times to remove the emulsifier and unencapsulated drug. The resulting particles were resuspended in $10 \mathrm{~mL}$ of deionized water and freeze-dried. The fluorescent coumarin 6-loaded PCL-Tween 80 nanoparticles were prepared in the same way, except that $0.1 \%(\mathrm{w} / \mathrm{v})$ coumarin 6 was encapsulated instead of docetaxel. Docetaxel-loaded PCL nanoparticles were prepared by the same procedure.

\section{Nanoparticle characterization}

\section{Particle size and zeta potential}

The particle size and size distribution of the nanoparticles were measured by dynamic light scattering (Zetasizer Nano ZS90, Malvern Instruments Ltd, Worcestershire, UK). The dried particles (about $2 \mathrm{mg}$ ) were suspended in deionized water before measurement. The zeta potential of the nanoparticles was determined by laser Doppler anemometry (Zetasizer Nano ZS90). The measurement was performed in triplicate.

\section{Surface morphology}

The surface morphology of the nanoparticles was observed by field emission scanning electron microscopy using a JEOL JSM-6700F system (JEOL, Tokyo, Japan) operated at a $5.0 \mathrm{kV}$ accelerating voltage. To prepare samples for field emission scanning electron microscopy, a drop of the particle suspension was placed on a grid or stud, and the supernatant liquid was removed with a capillary after the particles were allowed to settle. The particles were then coated with a platinum layer using a JFC-1300 automatic fine platinum coater (JEOL) for 30 seconds.

\section{Drug content and encapsulation efficiency}

Drug loading content and encapsulation efficiency of the nanoparticles were determined by high-pressure liquid chromatography (LC 1200, Agilent Technologies, Santa Clara, CA) as described previously. ${ }^{25}$ In short, $5 \mathrm{mg}$ of the nanoparticles were dissolved in $1 \mathrm{~mL}$ dichloromethane under vigorous vortexing. The organic solution was transferred to $5 \mathrm{~mL}$ of mobile phase consisting of deionized water and acetonitrile (50:50, v/v). A nitrogen stream was introduced to evaporate the dichloromethane for about 15 minutes, and then a clear solution was obtained for highpressure liquid chromatographic analysis. A reverse-phase Inertsil ${ }^{\circledR} \mathrm{C}$-18 column $(150 \mathrm{~mm} \times 4.6 \mathrm{~mm}$, pore size $5 \mathrm{~mm}$, GL Science Inc, Tokyo, Japan) was used. The flow rate of the mobile phase was $1 \mathrm{~mL} /$ minute. The column effluent was detected at $227 \mathrm{~nm}$ with an ultraviolet-visible detector. The drug encapsulation efficiency was defined as the ratio between the amount of docetaxel encapsulated in the nanoparticles and that added in the process. Experiments were performed in triplicate, and results are expressed as the mean \pm standard deviation.

\section{In vitro release studies}

In this assay, $15 \mathrm{mg}$ aliquots of drug-loaded nanoparticles, weighed by an electronic balance (XS105DU, Mettler Toledo, Greifensee, Switzerland), were dispersed in $5 \mathrm{~mL}$ of release medium (phosphate buffer solution, $\mathrm{pH} 7.4$, containing $0.05 \% \mathrm{w} / \mathrm{v}$ Tween 80 ) to form a suspension. Tween 80 was used to increase the solubility of docetaxel in the buffer solution and avoid binding of docetaxel to the tube wall. The suspension was transferred into a regenerated cellulose dialysis membrane (Spectra/Por 6, molecular weight cutoff 1000, Spectrum, Houston, TX). The closed bag was then put into a centrifuge tube and immersed in $15 \mathrm{~mL}$ of release medium. The tube was put in an orbital water bath shaking at $120 \mathrm{rpm}$ and at $37^{\circ} \mathrm{C} ; 10 \mathrm{~mL}$ aliquots of solutions were periodically removed for analysis and replaced with fresh medium. The collected samples were extracted with $2 \mathrm{~mL}$ dichloromethane and reconstituted in a $5 \mathrm{~mL}$ mobile phase. A nitrogen stream was introduced to evaporate the dichloromethane. The analysis procedure was the same as for the measurement of drug encapsulation efficiency.

\section{In vitro cell test}

\section{Cell culture}

Glioma C6 cell lines were obtained from the American Tissue Culture Collection (Rockville, MD) and cultured using the methods described by Freshney. ${ }^{26}$ Briefly, cells 
$\left(10^{4}\right.$ cells $\left./ \mathrm{mL}\right)$ were seeded in $75 \mathrm{~cm}^{2}$ tissue culture flasks (15 mL/flask) with Dulbecco's modified Eagle medium supplemented with $10 \%$ fetal bovine serum and $1 \%$ antibiotic, and incubated at $37^{\circ} \mathrm{C}$ in a humidified environment of $5 \% \mathrm{CO}_{2}$.

\section{Cellular uptake assay}

The cell lines used in the study were cultured in a 96-well black bottom plate at a density of $5 \times 10^{3}$ cells/well for 24 hours, before addition of medium containing fluorescent nanoparticles at a series of concentrations, ie, 100, 200, and $500 \mu \mathrm{g} / \mathrm{mL}$, and incubation for another 2 hours. The cells were then washed three times with phosphate-buffered solution before dissolving in $0.5 \%$ Triton-X $100 \mathrm{NaOH}$ aqueous solution $(0.2 \mathrm{~N})$. Particle uptake by the cell monolayers was then determined by measuring the fluorescent intensity with a microplate reader. The fluorescent intensity of the coumarin 6-loaded nanoparticles was determined in a similar manner prior to the experiment. The results obtained were expressed as a percentage of the total number of coumarin 6-loaded nanoparticles found in the solubilized cells to the total number of coumarin 6-loaded nanoparticles applied to the cells.

For analysis using confocal laser scanning microscopy (Olympus Fluoview FV-1000, Olympus Optical Co, Ltd, Tokyo, Japan), the cells were first cultured on Lab-Tek ${ }^{\mathrm{TM}}$ chambered coverglass for 24 hours $\left(10^{4}\right.$ cells/chamber $)$. The cell monolayers were then incubated with medium containing PCL-Tween 80 nanoparticles $(200 \mu \mathrm{g} / \mathrm{mL})$ for 2 hours and rinsed three times with phosphate-buffered solution. After fixing with ethanol for 20 minutes, they were washed again with phosphate-buffered solution, and stained thereafter with 4',6-diamidino-2-phenylindole dihydrochloride (DAPI, Fluka, Buche, Switzerland) for 30 minutes and rinsed again to remove the free dye. The cells were then viewed and imaged by confocal laser scanning microscopy with imaging software. Images of the cells were determined with a differential interference contrast channel, and the images of coumarin 6-loaded nanoparticles and the nuclei of cells stained by DAPI were recorded using a blue channel (DAPI) with excitation at $340 \mathrm{~nm}$ and a green channel (coumarin 6) with excitation at $488 \mathrm{~nm}$.

\section{Cell viability assay}

In this study, in vitro cancer cell viability was assessed using an MTT toxic assay, which is widely used to evaluate the cytotoxic activity of drugs or biomaterials. This method is based on the capacity of living cells to metabolize the yellow tetrazolium salt, MTT, to a chromophore formazan product, the absorbance of which can be determined by spectrophotometric measurement. C6 glioma cells (passages 6-10) were used for in vitro evaluation of the cytotoxicity of docetaxelloaded PCL-Tween 80 nanoparticles in comparison with docetaxel formulated in Tween 80 (Taxotere) and docetaxelloaded PCL nanoparticles. The cells were cultured in $20 \mathrm{~mL}$ of Dulbecco's modified Eagle medium supplemented with $10 \%$ fetal bovine serum and $1 \%$ antibiotic-antimycotic in a $75 \mathrm{~cm}^{2}$ culture flask. The culture flask was incubated at $37^{\circ} \mathrm{C}$ in a humidified environment containing $5 \% \mathrm{CO}_{2}$. The medium was replenished every other day until confluency was reached. The cells were harvested with $0.125 \%$ of trypsin-ethylenediamine tetra-acetic acid solution and seeded in 96-well transparent plates (Costar, Corning, NY) at $4 \times 10^{4}$ cells/well.

When the cells seeded in the 96-well transparent plates are at about $70 \%$ confluence, the culture medium in the wells was replaced with $100 \mu \mathrm{L}$ of the drug-loaded nanoparticle suspension or Taxotere in fresh medium, with drug concentrations ranging from 0.25 to $25 \mu \mathrm{g} / \mathrm{mL}$ for 24 and 72 hours of incubation. The drug-loaded nanoparticles were sterilized by gamma irradiation before the cytotoxicity test. Six wells were used for each nanoparticle sample. One row of 12 wells was used as a positive control, in which only culture medium was added to the wells. At the designated times, medium containing the drug was removed and the cells were washed twice with $50 \mu \mathrm{L}$ of phosphate-buffered solution, after which $90 \mu \mathrm{L}$ of culture medium and $10 \mu \mathrm{L}$ of MTT were added to each of the wells. The cells were incubated for 3-4 hours and the solution was then removed from the precipitate. A total of $100 \mathrm{~mL}$ of 2-propanol was added to the wells and the level of absorbance was measured using a microplate reader. Untreated cells were used as a control with 100\% viability, and cells without addition of MTT were used as a blank to calibrate the spectrophotometer to zero absorbance.

\section{Statistical analyses}

The data were expressed as the mean \pm standard deviation. The significance of differences was assessed using the Student's $t$-test, with $P<0.05$ considered to indicate a statistically significant difference.

\section{Results and discussion Characterization of PCL-Tween 80 copolymer}

As shown in Figure 1, PCL-Tween 80 copolymers were synthesized by ring opening polymerization in the 


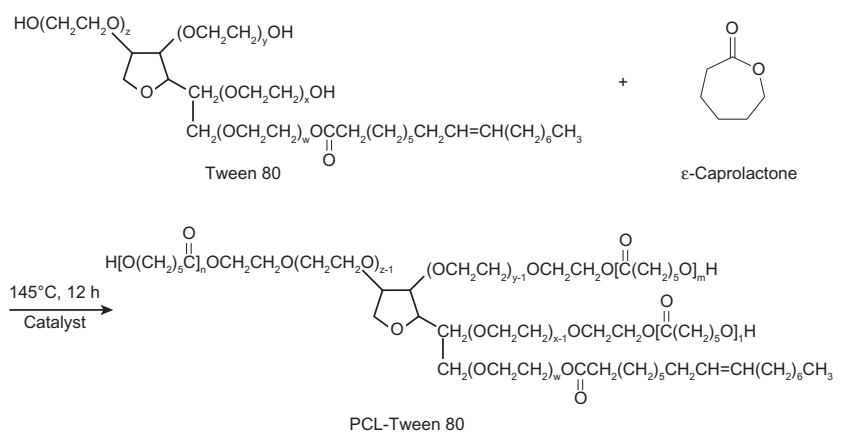

Figure I Schematic diagram of the synthesis of PCL-Tween 80 copolymer. Abbreviation: $\mathrm{PCL}$, poly- $\varepsilon$-caprolactone.

presence of $\varepsilon$-caprolactone and Tween 80 . The PCLTween 80 copolymer was then characterized by ${ }^{1} \mathrm{H}$ NMR in $\mathrm{CDCl}_{3}$, and the spectrum is shown in Figure 2. The peak at $3.65 \mathrm{ppm}$ could be attributed to the $-\mathrm{CH}_{2}$ protons of the polyethylene oxide part of Tween 80 in the copolymers. The small peaks in the aliphatic region belong to various moieties of $-\mathrm{CH}_{3}$ and $-\mathrm{CH}_{2}$ protons in the Tween 80 tails. The peaks at 4.06 (peak A), 2.31 (peak C), 1.60-1.70 (peak D), and 1.35-1.43 (peak E) were assigned to $-\mathrm{OCH}_{2}$ $-\mathrm{COCH}_{2},-\mathrm{CH}_{2}(4 \mathrm{H})$ and $-\mathrm{CH}_{2}(2 \mathrm{H})$ segments of PCL, respectively. ${ }^{25}$

Figure 3 shows the Fourier transform infrared spectra of the PCL-Tween 80 copolymer. In the PCL-Tween 80 spectrum, the carbonyl band of PCL-Tween 80 copolymer appears at $1729 \mathrm{~cm}^{-1}$. The bands in the range $2867-2950 \mathrm{~cm}^{-1}$ are assigned to the $-\mathrm{CH}_{2}$ stretching band of PCL. The absorption band at 3400-3650 $\mathrm{cm}^{-1}$ is attributed to the terminal hydroxyl group and that at $1044-1298 \mathrm{~cm}^{-1}$ is due to $\mathrm{C}-\mathrm{O}$ stretching. ${ }^{27}$ Of these, the band at $1243 \mathrm{~cm}^{-1}$ is assigned to asymmetric

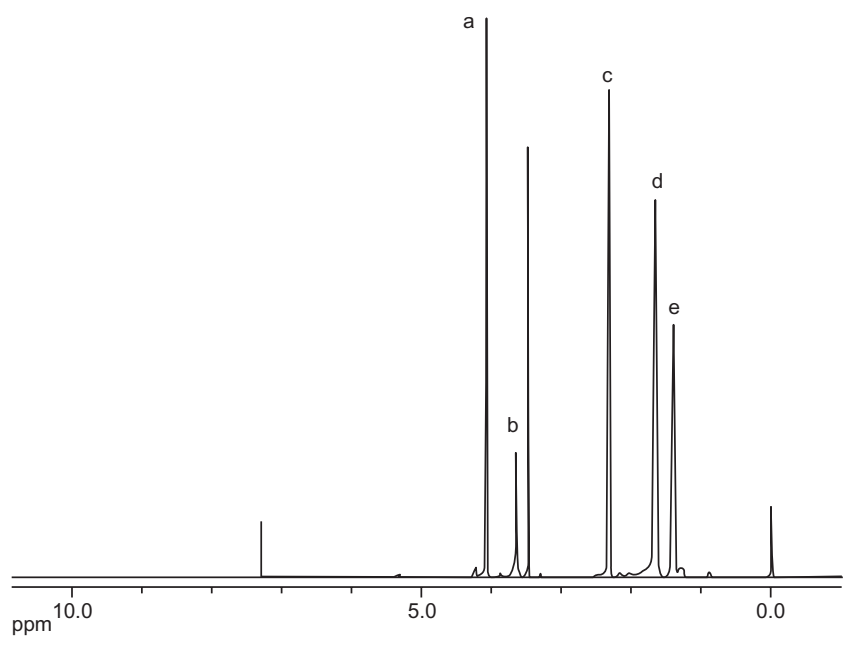

Figure 2 Typical 'H-NMR spectra of PCL-Tween 80 copolymer. Abbreviations: $\mathrm{PCL}$, poly- $\varepsilon$-caprolactone; NMR, nuclear magnetic resonance.

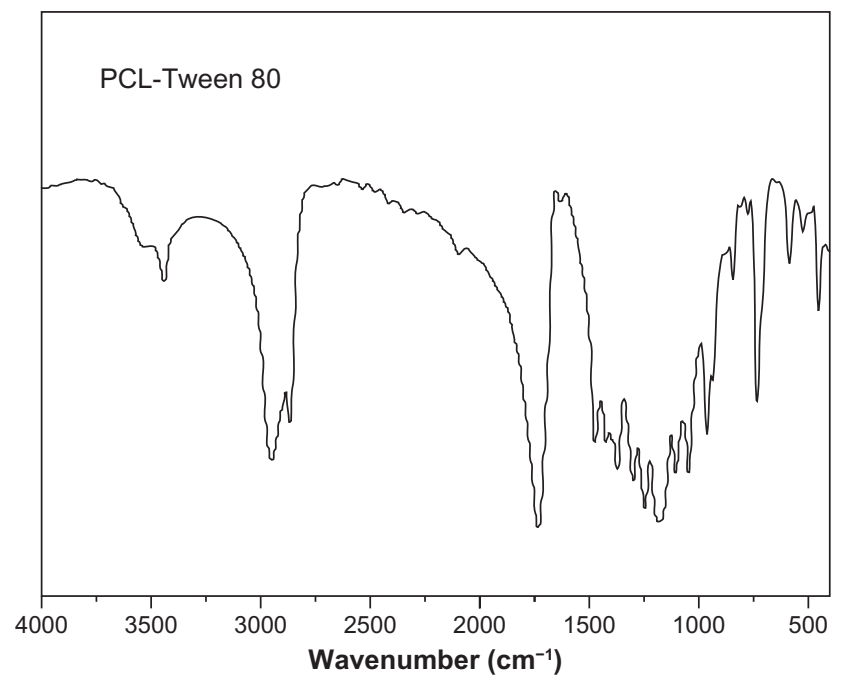

Figure 3 Fourier transform infrared spectra of PCL-Tween 80 copolymer. Abbreviation: $\mathrm{PCL}$, poly- $\varepsilon$-caprolactone.

COC stretching. ${ }^{28}$ The band at $1298 \mathrm{~cm}^{-1}$ has been used in the literature to investigate the crystallinity change in PCL. ${ }^{29}$ The results confirmed the successful synthesis of PCL-Tween 80 copolymer.

In the gel permeation chromatography analysis, we confirmed that the PCL-Tween 80 copolymer was synthesized by ring-opening polymerization. The product was not a physical mixture of Tween 80 and $\varepsilon$-caprolactone. The number-averaged molecular weight calculated from the gel permeation chromatograph was 21,656. The molecular weight of the PCL-Tween 80 copolymer could also be calculated using the ratio between the NMR peak areas at 1.35-1.43 (peak area 1.07) and 3.65 (peak area 0.23). The number-averaged molecular weight of the PCL-Tween 80 copolymer was determined to be 18,388 . It seems that the molecular weight detected by gel permeation chromatography and NMR were the same. In addition, the feeding ratio of $\varepsilon$-caprolactone and the Tween 80 molecular mass were $90 \%$ and $10 \%$, respectively. However, the ratio of $\varepsilon$-caprolactone and Tween 80 molecular mass integrated into the PCLTween 80 copolymer was $92.88 \%$ and $7.12 \%$.

Thermogravimetric analysis was performed on the synthesized copolymers to investigate their thermal properties. Figure 4 shows typical thermal degradation profiles for PCL-Tween 80 copolymer, which have two main regions of weight loss. Each turning point marked the combustion of a new component in the copolymers. The $200^{\circ} \mathrm{C}-420^{\circ} \mathrm{C}$ and $420^{\circ} \mathrm{C}-550^{\circ} \mathrm{C}$ combustion zones were attributed to the PCL and Tween 80 parts of the copolymers, respectively. These results further confirmed successful synthesis of PCL-Tween 80 copolymer. 


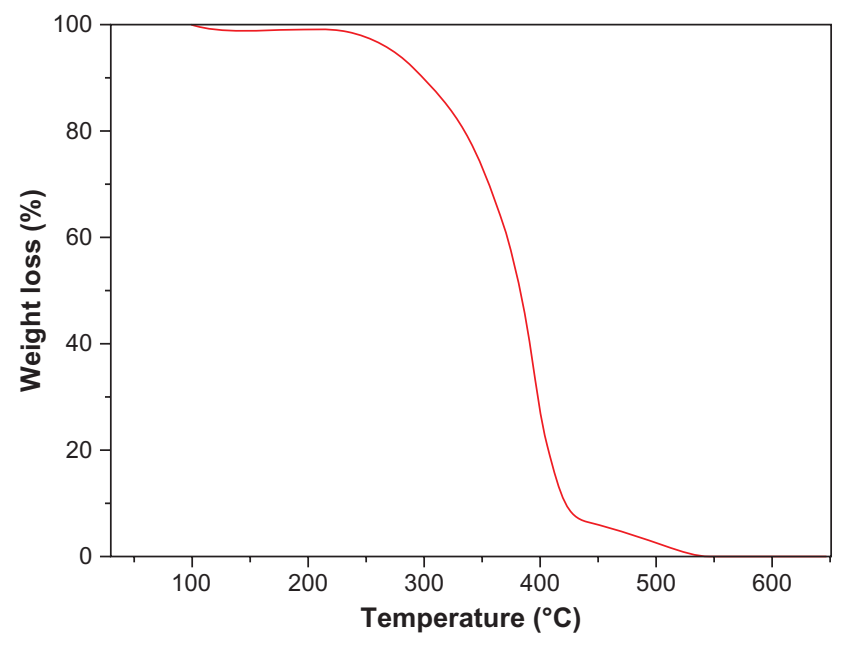

Figure 4 Thermogravimetric profiles of PCL-Tween 80 copolymer. Abbreviation: $\mathrm{PCL}$, poly- $\varepsilon$-caprolactone.

\section{Characterization of drug-loaded nanoparticles}

Size, zeta potential, and encapsulation efficiency

The particle size data for the docetaxel-loaded PCL-Tween 80 nanoparticles, drug-free PCL-Tween 80 nanoparticles, and docetaxel-loaded PCL nanoparticles fabricated in this study are shown in Table 1. Physicochemical characteristics, such as particle size and surface properties, play key roles in determining their in vitro drug release, cellular uptake, and cytotoxicity of these nanoparticles, as well as their in vivo pharmacokinetics and biodistribution, and thereby the therapeutic efficacy of the encapsulated drug. ${ }^{30-32}$ Permeability of the particles through the intestinal mucosa decreases with increasing particle size, reaching a cutoff at around $500 \mathrm{~nm} .{ }^{31}$ The resulting nanoparticles were $200-280 \mathrm{~nm}$ in diameter, which is in the size range favoring cellular uptake of nanoparticles. ${ }^{32}$ The average size of the PCL-Tween 80 nanoparticles was much smaller and the size distribution much narrower than that of the PCL nanoparticles. This may be due to the self-emulsifying function of the Tween 80 component in the copolymer. There was also evidence that the amphipathic Tween 80 surfactants align themselves at the oil-water interface to promote stability of the particles by lowering the surface energy and thus resisting particle coalescence and flocculation. ${ }^{25,32}$ It can be also seen from Table 1 that the PCL-Tween 80 nanoparticles could achieve around $80 \%$ drug encapsulation efficiency at $10 \%$ drug loading, which is much higher than that achieved by the PCL nanoparticles. The drug-loaded PCL-Tween 80 nanoparticles showed a negative surface charge of around $-20 \mathrm{mV}$. Compared with the PCL nanoparticles, the zeta potential of which is around $-13.55 \mathrm{mV}$, a great increase in the absolute value of the zeta potential could be observed for the PCL-Tween 80 nanoparticles, which may result in higher dispersion stability. The recent literature has reported that a higher absolute value of the zeta potential indicates a more stable suspension, and a lower value indicates colloid instability, which could lead to aggregation of nanoparticles..$^{33,34}$

\section{Surface morphology}

The surface morphology of the docetaxel-loaded PCL-Tween 80 nanoparticles was investigated by field emission scanning electron microscopy. Figure 5 shows the field emission scanning electron microscopic images for docetaxel-loaded PCLTween 80 nanoparticles. Further, these images confirmed the particle size determined by dynamic light scattering. Analysis of particle morphology revealed that the PCL-Tween 80 nanoparticles had a well defined spherical shape and were around $200 \mathrm{~nm}$ in diameter.

\section{In vitro drug release}

The in vitro drug release profiles for PCL and PCL-Tween 80 nanoparticles in the first 28 days are presented in Figure 6. A biphasic release pattern of drug release was observed from both polymeric nanoparticles. However, the drug release from the PCL-Tween 80 nanoparticles was found to be $25.76 \%$ and $34.90 \%$ of the encapsulated drug in the first 5 days and at 28 days, respectively, which was much faster than that of the PCL nanoparticles, ie, $18.25 \%$ and $24.73 \%$, respectively, for the same time periods. The more rapid drug release from the PCL-Tween 80 nanoparticles may be

Table I Characterization of nanoparticles $(n=3)$

\begin{tabular}{lllllll}
\hline Sample & Polymer & Theoretical drug loading & Size $(\mathbf{n m})$ & PDI & ZP (mV) & EE (\%) \\
\hline ANP & PCL-Tween 80 & $10 \%$ & $204.95 \pm 3.66$ & $0.201 \pm 0.23$ & $-20.14 \pm 0.15$ & $81.98 \pm 2.61$ \\
BNP & PCL-Tween 80 & 0 & $192.45 \pm 1.93$ & $0.163 \pm 0.17$ & $-18.33 \pm 0.31$ & 0 \\
CNP & PCL-Tween 80 & $*$ & $217.36 \pm 2.02$ & $0.241 \pm 0.09$ & $-22.25 \pm 0.29$ & Not shown \\
DNP & PCL & $10 \%$ & $258.48 \pm 5.95$ & $0.301 \pm 0.15$ & $-13.55 \pm 0.19$ & $71.44 \pm 3.61$ \\
ENP & PCL & $*$ & $223.33 \pm 3.33$ & $0.236 \pm 0.31$ & $-16.26 \pm 0.22$ & Not shown \\
\hline
\end{tabular}

Note: *Coumarin 6.

Abbreviations: PDI, polydispersity index; ZP, zeta potential; EE, encapsulation efficiency; ANP, PCL-Tween 80 nanoparticles; DNP, docetaxel-loaded PCL nanoparticles; BNP, drug-free PCL-Tween 80 nanoparticles; ENP, coumarin 6-loaded PCL nanoparticles; CNP, coumarin 6-loaded PCL-Tween 80 nanoparticles. 


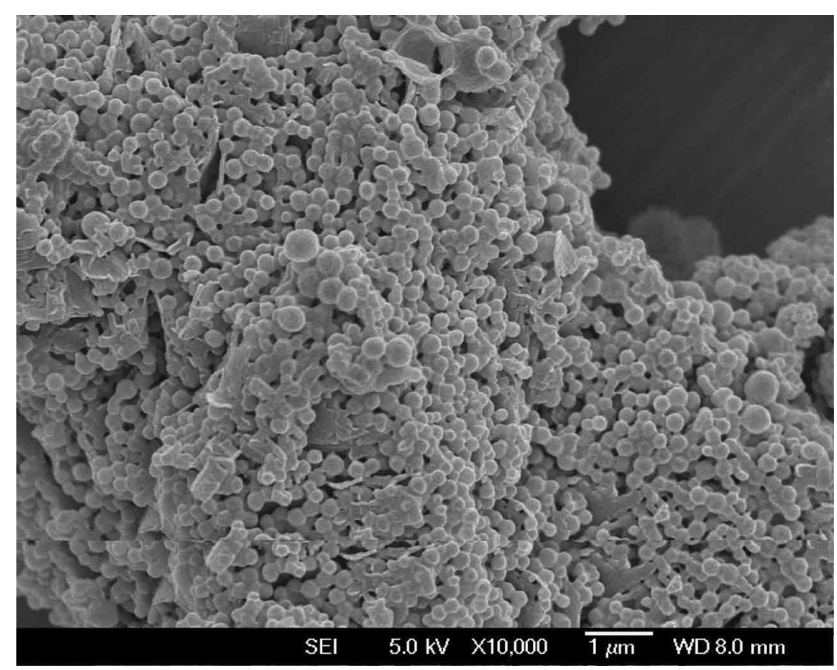

Figure 5 Field emission scanning electron microscopy image of docetaxel-loaded PCL-Tween 80 nanoparticles.

Abbreviation: $\mathrm{PCL}$, poly- $\varepsilon$-caprolactone.

attributable to the lower molecular weight and higher hydrophilicity of the PCL-Tween 80 copolymer in comparison with the PCL nanoparticles.

\section{Uptake of coumarin 6-loaded nanoparticles by $\mathrm{C} 6$ cells}

A C6 glioma cell line was used to investigate the uptake of polymeric nanoparticles by brain cancer cells. It is becoming clear that the therapeutic effects of drug-loaded nanoparticles would depend on internalization and sustained retention of the nanoparticles by diseased cells. ${ }^{18-35}$ Fluorescence uptake by $\mathrm{C} 6$ cells could be a useful model for assessing the in vitro therapeutic effect of various docetaxel formulations

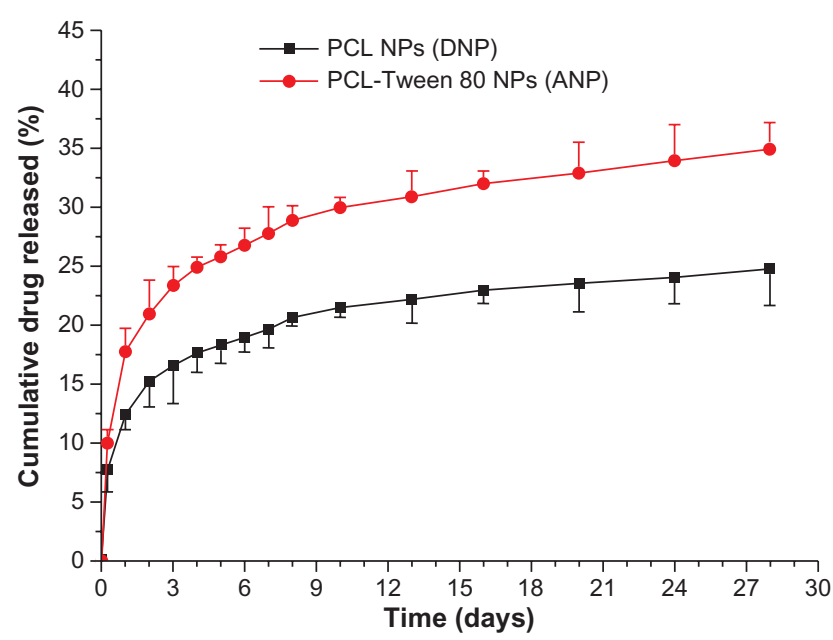

Figure 6 In vitro release profile of docetaxel-loaded PCL-Tween 80 nanoparticles and docetaxel-loaded PCL nanoparticles.

Abbreviations: PCL, poly- $\varepsilon$-caprolactone; NPs, nanoparticles. for brain cancer. As shown in Table 1, the coumarin 6-loaded nanoparticles used for cellular uptake research were highly relevant to the docetaxel-loaded nanoparticles in terms of their size and zeta potential. Thus, cellular uptake of coumarin 6-loaded PCL-Tween 80 nanoparticles and PCL nanoparticles was compared in this research using a C6 model brain cancer cell line. Uptake of coumarin 6-loaded nanoparticles by $\mathrm{C} 6$ cells was assayed following 2 hours of incubation, and the results are shown in Figure 7. The cellular nanoparticle uptake efficiency in C6 cells was found to be dose-dependent for both formulations. The cellular uptake efficiency of PCL-Tween 80 nanoparticles was 1.63 -fold, 1.76-fold, and 1.74-fold higher than that of PCL nanoparticles at incubated particle concentrations of 100, 250, and $500 \mu \mathrm{g} / \mathrm{mL}$, respectively. It has been reported that the uptake of Tween 80 -coated nanoparticles by bovine brain capillary cells is better than that of uncoated particles. ${ }^{36}$ Furthermore, it has been demonstrated that the mechanism of cellular uptake for biodegradable microparticles or nanoparticles is size-dependent. ${ }^{18,37}$ Thus, it is reasonable to expect that PCLTween 80 nanoparticles would have a higher cellular uptake due to the Tween 80 coating and their smaller particle size.

Figure 8 shows confocal laser scanning microscopic images of $\mathrm{C} 6$ cells after 2 hours of incubation with coumarin 6-loaded PCL-Tween 80 nanoparticles at a $200 \mu \mathrm{g} / \mathrm{mL}$ concentration. The images were obtained from the DAPI (blue) channel, the green fluorescent protein (green) channel, and the overlay of the two channels. It can be observed from Figure 8 that the fluorescence of the coumarin 6-loaded PCL-Tween 80 nanoparticles (green) is located in the cytoplasm around the nucleus (blue, stained by DAPI),

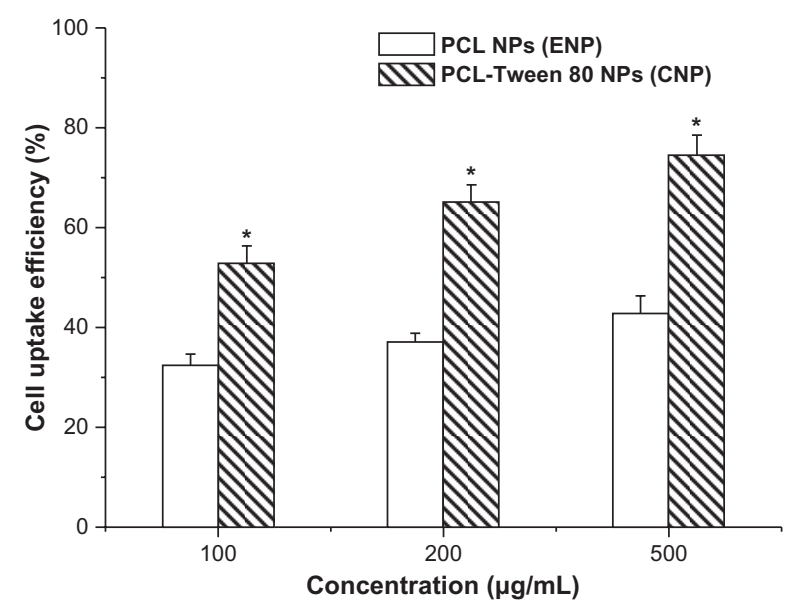

Figure 7 Cellular uptake of coumarin 6-loaded PCL-Tween 80 nanoparticles and coumarin 6-loaded PCL nanoparticles by $\mathrm{C} 6$ cells after 2 hours of incubation.

Note: $* P<0.05$.

Abbreviation: $\mathrm{PCL}$, poly- $\varepsilon$-caprolactone. 


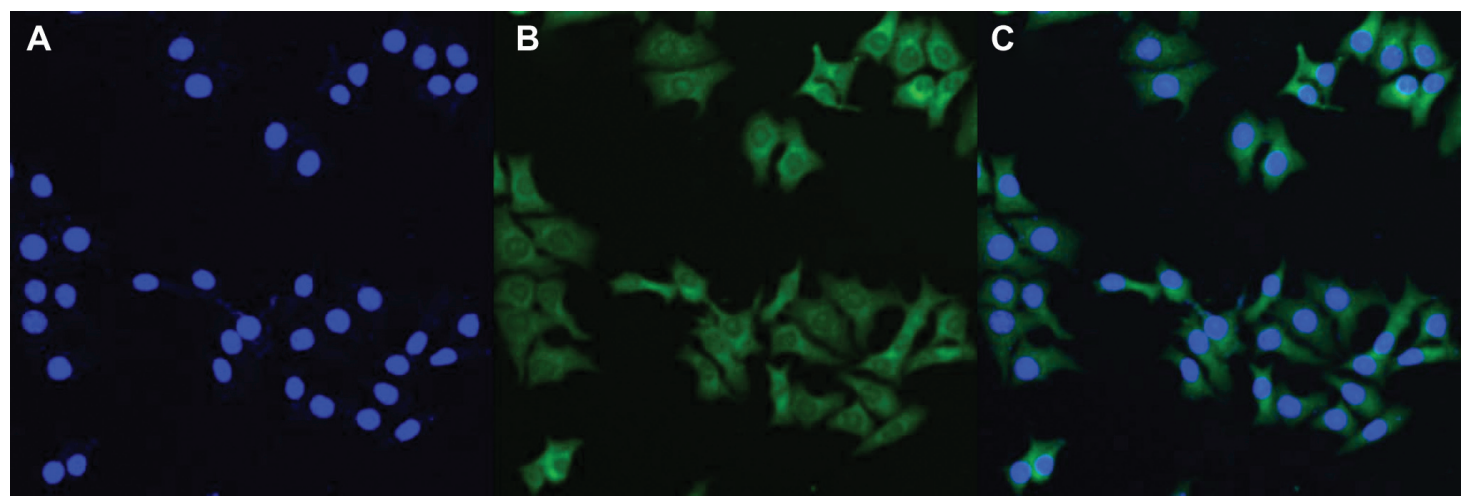

Figure 8 Confocal laser scanning microscopy images of C6 cells after 2 hours of incubation with coumarin 6-loaded PCL-Tween 80 nanoparticles at $37.0^{\circ} \mathrm{C}$. The cells were stained by DAPI (blue) and the coumarin 6-loaded nanoparticles are green. The cellular uptake was visualized by overlaying images obtained by green fluorescent protein filter and DAPI filter: left image from DAPI channel (A); center image from green fluorescent protein channel (B); right image from combined green fluorescent protein channel and DAPI channel (C).

Abbreviation: $\mathrm{PCL}$, poly- $\varepsilon$-caprolactone.

indicating that the nanoparticles have been internalized into the cells.

\section{Assessment of nanoparticle cytotoxicity}

A C6 glioma cell line was also used to investigate the cytotoxicity of the docetaxel-loaded copolymers, which was compared with that for the commercial formulation, ie, Taxotere. The drug-loaded nanoparticles were sterilized by gamma radiation to exclude any sample contamination effect, and were then suspended and cultured with the $\mathrm{C} 6$ cells. Figure 9 shows the viability of C6 cells after 24, 48, and 72 hours of cell culture with docetaxel formulated in the PCL-Tween 80 nanoparticles
A

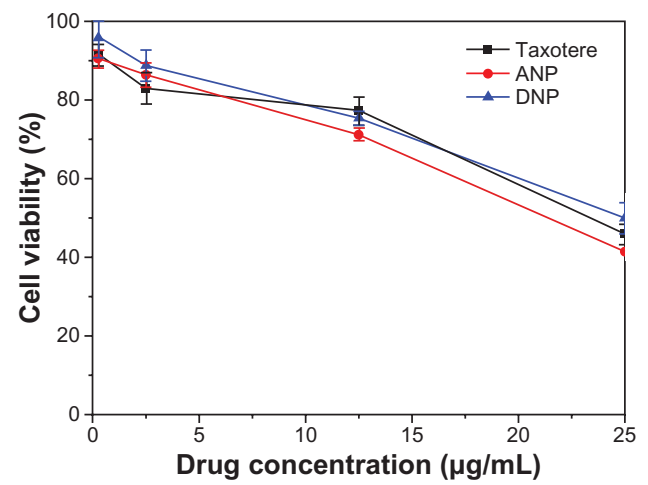

B

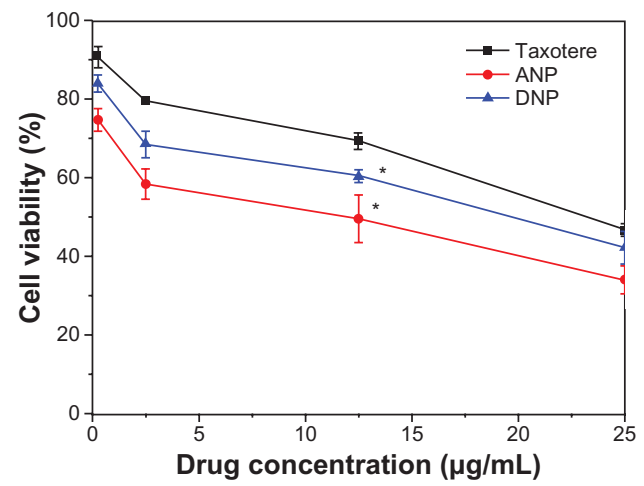

C

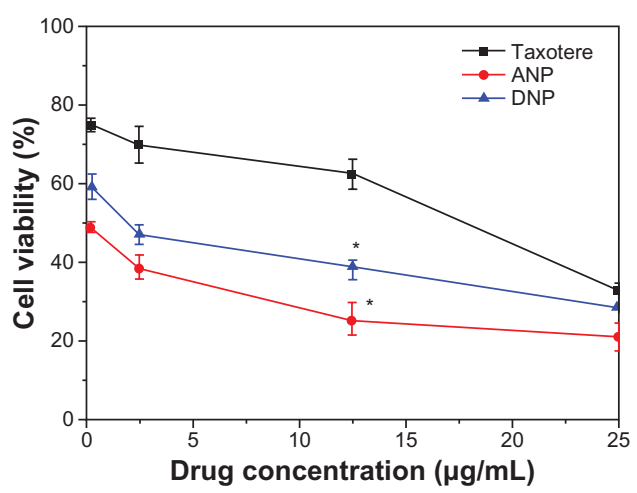

Figure 9 Viability of C 6 cells after $24(\mathbf{A}), 48(\mathbf{B})$, and $72(\mathbf{C})$ hours of cell culture with docetaxel formulated in ANP and DNP in comparison with Taxotere ${ }^{\circledR}$ at the same docetaxel dose.

Note: $\mathrm{n}=6, * \mathrm{P}<0.05$.

Abbreviations: PCL, poly- $\varepsilon$-caprolactone; ANP, PCL-Tween 80 nanoparticles; DNP, PCL nanoparticles. 
and PCL nanoparticles, respectively, in comparison with that of the Taxotere formulation at the same $0.25,2.5,12.5$, and $25 \mu \mathrm{g} / \mathrm{mL}$ docetaxel dose $(\mathrm{n}=6)$. It can be concluded from Figure 9 that both nanoparticle formulations have advantages in decreasing cancer cell viability versus the current clinical dosage form, and that PCL-Tween 80 nanoparticles can have even better effects than PCL nanoparticles. For example, viability of $\mathrm{C} 6$ cells after 24 hours of incubation at the $12.5 \mu \mathrm{g} / \mathrm{mL}$ drug concentration was $77.45 \%$ for Taxotere, $71.22 \%$ (ie, a $27.63 \%$ increase in cytotoxicity) for PCLTween 80 nanoparticles, and $75.75 \%$ (ie, a $7.54 \%$ increase in cytotoxicity) for PCL nanoparticles. Furthermore, compared with Taxotere, the cytotoxicity of C6 cells was increased by $64.52 \%(P<0.05, \mathrm{n}=6)$ and $98.88 \%(P<0.05, \mathrm{n}=6)$ for PCL-Tween 80 nanoparticles after 48 and 72 hours of incubation at the $12.5 \mu \mathrm{g} / \mathrm{mL}$ drug concentration, respectively. Such advantages of the nanoparticle formulations may have contributed to the effects of the Tween 80 component in enhancing cellular uptake of the nanoparticles. The advantage of cancer cell viability of the PCL-Tween 80 nanoparticles $>$ PCL nanoparticles $>$ the Taxotere formulation is dependent on incubation time and drug concentration. As time went on, both nanoparticle formulations showed better in vitro therapeutic effects in $\mathrm{C} 6$ cells than commercial Taxotere. This may be contributed to by the controlled-release characteristics of the nanoparticle formulation. For example, the cumulative drug release was only $17.71 \%, 20.90 \%$, and $23.33 \%$ for PCL-Tween 80 nanoparticles after 24, 48, and 72 hours (Figure 6), respectively, and the release started from $0 \%$, while Taxotere immediately became $100 \%$ available for the C6 cells in culture.

\section{Conclusion}

A novel PCL-Tween 80 copolymer was successfully synthesized in this research. PCL-Tween 80 nanoparticles were prepared by a modified solvent extraction/evaporation method. Docetaxel was chosen as the prototype anticancer drug due to its excellent therapeutic activity against a wide spectrum of cancers. The nanoparticles were found by field emission scanning electron microscopy to be of spherical shape and around $200 \mathrm{~nm}$ in diameter. The copolymers could encapsulate $10 \%$ of the drug in the nanoparticles and had released $34.9 \% \pm 2.23 \%$ of the drug by 28 days. The PCL-Tween 80 nanoparticles could be internalized into cells and had higher cellular uptake than PCL nanoparticles. The drug-loaded PCL-Tween 80 nanoparticles showed better in vitro cytotoxicity towards C6 glioma cells than commercial Taxotere at the same drug concentration. However, the effects of the nanoparticle formulation should actually be better given their controlled-release features. Further in vivo investigations, including pharmacokinetics, biodistribution, pharmacodynamics, and toxicity, will be carried out to evaluate the potential of these copolymer nanoparticles to be used as drug delivery vehicles.

\section{Acknowledgments}

The authors are grateful for the financial support of the National Natural Science Foundation of China (No. 30900291), China Postdoctoral Science Special Foundation (No. 201003127), Natural Science Foundation of Guangdong Province (No. 10451805702004178), Shenzhen Science, Industry, Trade and Information Technology Commission, and Shenzhen Nanshan Science and Technology Program (No. KJ02S0210900000109). The project was also sponsored by open funds from the State Key Laboratory of Oncology in South China.

\section{Disclosure}

The authors report no conflicts of interest in this work.

\section{References}

1. Panagi Z, Beletsi A, Evangelatos G, et al. Effect of dose on the biodistribution and pharmacokinetics of PLGA and PLGA-mPEG nanoparticles. Int J Pharm. 2001;221:143-152.

2. Gindy ME, Prud'homme RK. Multifunctional nanoparticles for imaging, delivery and targeting in cancer therapy. Expert Opin Drug Deliv. 2009;6:865-878

3. Dunn SE, Coombes AGA, Garnett MC, et al. In vitro cell interaction and in vivo biodistribution of poly(lactide-co-glycolide) nanospheres surface modified by poloxamer and poloxamine copolymers. $J$ Control Release. 1997;44:65-76.

4. Zhang Z, Feng SS. In vitro investigation on poly(lactide)-Tween 80 copolymer nanoparticles fabricated by dialysis method for chemotherapy. Biomacromolecules. 2006;7:1139-1146.

5. Ma Y, Zheng Y, Liu K, et al. Nanoparticles of poly(lactide-co-glycolide)d-a-tocopheryl polyethylene glycol 1000 succinate random copolymer for cancer treatment. Nanoscale Res Lett. 2010;5:1161-1169.

6. Gref R, Minamitake Y, Peracchia MT, et al. Biodegradable longcirculating polymeric nanospheres. Science. 1994;263:1600-1603.

7. Kreuter J. Nanoparticulate systems for brain delivery of drugs. $A d v$ Drug Deliv Rev. 2001;47:65-81.

8. Das D, Lin SS. Double-coated poly (butylcynanoacrylate) nanoparticulate delivery systems for brain targeting of dalargin via oral administration. J Pharm Sci. 2005;94:1343-1353.

9. Sun WQ, Xie CS, Wang HF, et al. Specific role of polysorbate 80 coating on the targeting of nanoparticles to the brain. Biomaterials. 2004;25: 3065-3071.

10. Koziara JM, Lockman PR, Allen DD, et al. In situ blood-brain barrier transport of nanoparticles. Pharm Res. 2003;20:1772-1778.

11. Kreuter J. Influence of the surface properties on nanoparticle-mediated transport of drugs to the brain. J Nanosci Nanotechnol. 2004;4: 484-488.

12. Kreuter J, Shamenkov D, Petrov V, et al. Apolipoprotein-mediated transport of nanoparticle-bound drugs across the blood-brain barrier J Drug Target. 2002;10:317-325.

13. Calvo P, Gouritin B, Chacun H, et al. Long-circulating PEGylated polycyanoacrylate nanoparticles as new drug carrier for brain delivery. Pharm Res. 2001;18:1157-1166. 
14. Alyautdin RN, Tezikov EB, Ramge P, et al. Significant entry of tubocurarine into the brain of rats by adsorption to polysorbate 80 -coated polybutylcyanoacrylate nanoparticles: an in situ brain perfusion study. J Microencapsul. 1998;15:67-74.

15. Schroder U, Sabel BA. Nanoparticles, a drug carrier system to pass the blood-brain barrier, permit central analgesic effects of i.v. dalargin injections. Brain Res. 1996;710:121-124.

16. Gulyaev AE, Gelperina SE, Skidan IN, et al. Significant transport of doxorubicin into the brain with polysorbate 80 -coated nanoparticles. Pharm Res. 1999;16:1564-1569.

17. Ema M, Hara H, Matsumoto M, et al. Evaluation of developmental neurotoxicity of polysorbate 80 in rats. Reprod Toxicol. 2008;25:89-99.

18. Mei L, Zhang Y, Zheng Y, et al. A novel docetaxel-loaded poly ( $\varepsilon$-caprolactone)/pluronic F68 nanoparticle overcoming multidrug resistance for breast cancer treatment. Nanoscale Res Lett. 2009;4: $1530-1539$.

19. Esmaeili F, Dinarvand R, Ghahremani MH, et al. Docetaxel-albumin conjugates: preparation, in vitro evaluation and biodistribution studies. J Pharm Sci. 2009;98:2718-2730.

20. Feng SS, Mei L, Anitha P, et al. Poly(lactide)-vitamin E derivative/ montmorillonite nanoparticle formulations for the oral delivery of docetaxel. Biomaterials. 2009;30:3297-3306.

21. Immordino ML, Brusa $P$, Arpicco S, et al. Preparation, characterization, cytotoxicity and pharmacokinetics of liposomes containing docetaxel. J Control Release. 2003;91:417-429.

22. Hwang HY, Kim IS, Kwon IC, et al. Tumor targetability and antitumor effect of docetaxel-loaded hydrophobically modified glycol chitosan nanoparticles. J Control Release. 2008;128:23-31.

23. Liu B, Yang M, Li R, et al. The antitumor effect of novel docetaxel-loaded thermosensitive micelles. Eur J Pharm Biopharm. 2008;69:527-534.

24. Du W, Hong L, Yao T, et al. Synthesis and evaluation of water-soluble docetaxel prodrugs-docetaxel esters of malic acid. Bioorg Med Chem. 2007; 15:6323-6330.

25. Ma Y, Huang LQ, Song CX, et al. Nanoparticle formulation of poly( $\varepsilon$-caprolactone-co-lactide)-d- $\alpha$-tocopheryl polyethylene glycol 1000 succinate random copolymer for cervical cancer treatment. Polymer. 2010;51:5952-5959.
26. Freshney RI. Culture of Animal Cells: A Manual of Basic Technique. New York, NY: Alan R Liss; 1983.

27. Liu K, Kiran E. High-pressure solution blending of poly(-caprolactone) with poly(methyl methacrylate) in acetone + carbon dioxide. Polymer. 2008;49:1555-1561.

28. Li SH, Woo EM. Immiscibility with upper-critical solution temperature phase diagrams for poly(methyl methacrylate)/polyesters blends. Colloid Polym Sci. 2008;286:253-265.

29. Elzein T, Nasser-Eddine M, Delaite C, et al. FTIR study of polycaprolactone chain organization at interfaces. J Colloid Interface Sci. 2004;273:381.

30. Alexis F, Pridgen E, Molnar LK, et al. Factors affecting the clearance and biodistribution of polymeric nanoparticles. Mol Pharm. 2008;5:505-515.

31. Florence AT. Nanoparticle uptake by the oral route: Fulfilling its potential? Drug Discov Today. 2005;2:75-81.

32. Yan F, Zhang C, Zheng Y, et al. The effect of Poloxamer 188 on nanoparticle morphology, size, cancer cell uptake, and cytotoxicity. Nanomedicine. 2010;6:170-178.

33. Scholes PD, Coombes AG, Illum L, et al. Detection and determination of surface levels of poloxamer and PVA surfactant on biodegradable nanospheres using SSIMS and XPS. J Control Release. 1999;59:261-278.

34. Zhang Y, Tang L, Sun L, et al. A novel paclitaxel-loaded poly ( $\varepsilon$-caprolactone)/Poloxamer 188 blend nanoparticle overcoming multidrug resistance for cancer treatment. Acta Biomater. 2010;6: 2045-2052.

35. Jin C, Bai L, Wu H, et al. Radiosensitization of paclitaxel, etanidazole and paclitaxel + etanidazole nanoparticles on hypoxic human tumor cells in vitro. Biomaterials. 2007;28:3724-3730.

36. Ramge P, Unger RE, Oltrogge JB, et al. Polysorbate- 80 coating enhances uptake of polybutylcyanoacrylate (PBCA)-nanoparticles by human and bovine primary brain capillary endothelial cells. Eur J Neurosci. 2000;12:1931-1940.

37. Davda J, Labhasetwar V. Characterization of nanoparticle uptake by endothelial cells. Int J Pharm. 2010;233:51-59.
International Journal of Nanomedicine

\section{Publish your work in this journal}

The International Journal of Nanomedicine is an international, peerreviewed journal focusing on the application of nanotechnology in diagnostics, therapeutics, and drug delivery systems throughout the biomedical field. This journal is indexed on PubMed Central, MedLine, CAS, SciSearch $\AA$, Current Contents ${ }^{\circledR} /$ Clinical Medicine,

\section{Dovepress}

Journal Citation Reports/Science Edition, EMBase, Scopus and the Elsevier Bibliographic databases. The manuscript management system is completely online and includes a very quick and fair peer-review system, which is all easy to use. Visit http://www.dovepress.com/ testimonials.php to read real quotes from published authors. 